\title{
VARIABILITY OF HMA CHARACTERISTICS AND ITS INFLUENCE ON PAY ADJUSTMENT
}

\author{
Filippo Giammaria PRATICÒ, Antonio CASCIANO \\ University Mediterranea of Reggio Calabria, Via Graziella - Feo di Vito, 89100, Italy.
}

Received 03 Mar 2012; accepted 16 Aug 2012

\begin{abstract}
The goal of this paper is to formalize and validate a model in order to determine a pay adjustment on the basis of mechanical and functional performance of transportation infrastructures. A model to determine the pay adjustment based on life expectancy of a pavement and the variability of its main properties was formulated. Five different paths and points of view are used in order to obtain information on model suitability and robustness. An algorithm has been proposed to estimate a pay adjustment (PA, negative or positive), based on life cycle cost analysis, when both structural and non-structural deficiencies/surplus in characteristics are detected. The five different methodologies, used for deriving PA, demonstrate the validity of the model in which the PA depends on both position and dispersion measures. It has been demonstrated that the model can help in analysing a project and construction management under a common framework. Analyses and validation demonstrate that the proposed model can efficiently overcome typical problems in PA determination and in contract administration, where decisions based upon objective and sound criteria are needed. Both practitioners and researchers are expected to benefit from the outcomes of this study.
\end{abstract}

Keywords: financial engineering, pay adjustment, transportation infrastructure, externality, boundary conditions, pavement.

\section{Introduction (PA - variability)}

Material properties and other characteristics of a constructed pavement will generally vary somewhat from those specified in contract because construction operations and materials are influenced by many factors (Table 1).

Each property and characteristic of a flexible pavement can affect its performance such as the derivation of a pay adjustment when the as-designed performance differs from the as-constructed performance (Mladenovic et al. 2003; Seebaly, Bazi 2005; Praticò 2007; Praticò, Moro 2007; D’Apuzzo, Nicolosi 2010).

The modulus and thickness of hot mix asphalt layers (usually wearing, binder and base courses) greatly affect the expected life of a pavement.

Critical analysis responses, such as pavement surface deflection and horizontal tensile strain at the bottom of the HMA layer, depend on pavement layers (Khazanovich et al. 2006).

High standard deviations can be detected both in terms of moduli (values as high as $3 \mathrm{GPa}$ can be detected for HMAs, or as high as $0.01 \mathrm{GPa}$ for unbound materials, see Table 1) and thickness (standard deviation can raise up to $70-110 \mathrm{~mm}$ for HMAs or unbound materials).
In the same way, surface and functional properties of wearing courses present an appreciable variance and relevance for both rigid and flexible pavements (Boscaino, Praticò 2001; Boscaino et al. 2009; Praticò et al. 2009; Gedafa et al. 2012).

All these facts affect construction statistics and in particular location measures (such as averages) and dispersion measures (such as standard deviation) of many quality characteristics (such as thickness or air void content). Quality characteristics (such as air void content) and quality measures (such as average, defect percentage) are generally used by highway agencies for the acceptance of pavement construction.

For these reasons, many highway agencies incorporate quality-related pay adjustments, in the form of incentives/disincentives, in construction contracts of flexible and rigid pavements to account for the loss or gain of money by the agency.

A recurring problem is that many of the approaches used by highway agencies dealing with construction variance and assessing pay adjustment have been empirically developed without a relationship to a logic well-grounded performance. These approaches use procedures and conceptual frameworks which are

Corresponding author: Filippo Giammaria Praticò

E-mail: filippo.pratico@unirc.it 
Table 1. Variability data

\begin{tabular}{|c|c|c|c|c|}
\hline Variable & $\begin{array}{l}\text { Unit of } \\
\text { measure }\end{array}$ & Standard Deviation & Coeff. of Variation (\%) & Reference \\
\hline \multirow{10}{*}{$\begin{array}{l}\text { Hot mix asphalt } \\
\text { (HMA) } \\
\text { modulus }\end{array}$} & \multirow{10}{*}{$\mathrm{GPa}$} & $0.04-0.97$ & $0.2-14.8$ & Carvalho (2006) \\
\hline & & 1.44 & 86.21 & Haider (2009) \\
\hline & & 0.37 & $10-0$ & Kim, Buch (2003) \\
\hline & & $0.26-0.40$ & $29-37$ & Kenis, Wang (2000) \\
\hline & & $0.06-0.27$ & $8-33$ & Mohammad et al. (2004) \\
\hline & & $0.1-3.19$ & $6.6-73$ & Stubstad et al. (2002) \\
\hline & & 0.69 & 15.48 & Retherford, McDonald (2010) \\
\hline & & - & $9.7-51.3$ & Arafah (1997) \\
\hline & & 0.14 & $0.1-164.5$ & Aguiar-Moya, Prozzi (2011) \\
\hline & & - & $1.2-2.2$ & \\
\hline \multirow{3}{*}{ Base course modulus } & \multirow{3}{*}{$\mathrm{GPa}$} & - & $5-60$ & Kim, Buch (2003) \\
\hline & & $0.051-0.055$ & $23-25$ & Kenis, Wang (2000) \\
\hline & & $0.001-0.081$ & $2-56$ & Stubstad et al. (2002) \\
\hline \multirow{3}{*}{$\begin{array}{l}\text { Modulus of unbound } \\
\text { granular base }\end{array}$} & \multirow{3}{*}{$\mathrm{GPa}$} & 0.014 & $5-60$ & Kim, Buch (2003) \\
\hline & & $0.008-0.011$ & $9-10$ & Kenis, Wang (2000) \\
\hline & & 0.006 & $0.8-89.6$ & Aguiar-Moya, Prozzi (2011) \\
\hline \multirow{10}{*}{ Thickness of HMA layer } & \multirow{10}{*}{$\mathrm{mm}$} & 12.2 & 15.5 & Darter et al. (1973) \\
\hline & & 10.4 & - & Sherman (1971) \\
\hline & & $6.6-12.45$ & $3.2-12.4$ & Stubstad et al. (2002) \\
\hline & & $6.33-6.81$ & $7-8$ & Kenis, Wang (2000) \\
\hline & & 54.88 & $3-37$ & Kim, Buch (2003) \\
\hline & & 12.20 & 15.48 & Retherford, McDonald (2010) \\
\hline & & - & $7.8-25.6$ & Attoh-Okine, Kim (1994) \\
\hline & & $8.38-18.29$ & $11.7-16$ & Aguiar-Moya, Prozzi (2011) \\
\hline & & $0.87-110.23$ & $0.62-83.19$ & Selezneva et al. (2002) \\
\hline & & $3.07-9.65$ & $4.85-19.18$ & Hughes et al. (1997) \\
\hline \multirow{4}{*}{$\begin{array}{l}\text { Thickness of HMA } \\
\text { wearing course }\end{array}$} & \multirow{4}{*}{$\mathrm{mm}$} & $8.55-31.50$ & $10.27-35.74$ & Haider (2009) \\
\hline & & $6.8-36.8$ & $24.56-30.41$ & Whiteley et al. (2005) \\
\hline & & $8.38-18.29$ & $3.2-18.4$ & Aguiar-Moya, Prozzi (2011) \\
\hline & & $0.52-107.46$ & $0.69-93.24$ & Selezneva et al. (2002) \\
\hline \multirow{7}{*}{$\begin{array}{l}\text { Thickness of unbound } \\
\text { granular base }\end{array}$} & \multirow{7}{*}{$\mathrm{mm}$} & 20.07 & - & Sherman (1971) \\
\hline & & $22.80-70.94$ & $11.12-28.04$ & Haider (2009) \\
\hline & & $8.58-9.50$ & $4-5$ & Kenis, Wang (2000) \\
\hline & & 31.75 & 10 & Retherford, McDonald (2010) \\
\hline & & 20.06 & 10 & Darter et al. (1973) \\
\hline & & 36.58 & $6-17.2$ & Aguiar-Moya, Prozzi (2011) \\
\hline & & $3.20-55.76$ & $1.90-37.44$ & Selezneva et al. (2002) \\
\hline \multirow{5}{*}{ Air void content } & \multirow{5}{*}{$\%$} & $0.2-2.1$ & $2-26.4$ & Mohammad et al. (2004) \\
\hline & & 0.36 & $0.9-39$ & Aguiar-Moya, Prozzi (2011) \\
\hline & & $0.49-1.11$ & - & Katicha et al. (2011) \\
\hline & & $0.39-0.90$ & $8.91-29.03$ & Hughes et al. (2007) \\
\hline & & $0.63-1.09$ & $10.67-26.05$ & Hughes et al. (1997) \\
\hline \multirow{4}{*}{ Asphalt binder content } & \multirow{4}{*}{$\%$} & 0.32 & $0.9-39.2$ & Aguiar-Moya, Prozzi (2011) \\
\hline & & $0.25-0.45$ & - & Katicha et al. (2011) \\
\hline & & $0.07-0.25$ & $1.18-26.7$ & Hughes et al. (2007) \\
\hline & & $0.17-0.27$ & $3.73-6.44$ & Hughes et al. (1997) \\
\hline
\end{tabular}


different from the ones used in project management and pavement design.

The real effect of standard deviation of material properties and other characteristics on agency costs and therefore pay adjustment is still unclear.

For the above issues in this paper a model to determine the pay adjustment based on life expectancy of a pavement and the variability of its main properties was formulated. Five different paths and points of view are used in order to obtain information on model suitability and robustness.

This paper is organized as follows. Section 1 deals with the methodology set out to derive and demonstrate the model, Section 1.1 refers to the overall methodology, Section 1.2 the new algorithm to derive PA based on E,
Section 1.3 to 1.7 five different paths/methods to estimate PA based on material quality. Section 2 describes and analyses the results obtained. The final section deals with conclusions and points out future research directions.

\section{Methodology}

Figure 1 summarizes the methodology. The $5^{\text {th }}$ path refers to the model set out herein.

\subsection{Framework of the methodology}

Air void content (AV) was considered as the main quality characteristic.

In the first case $\left(1^{\text {st }}\right.$ path $)$, the expected life of the pavement $(\mathrm{E})$ is derived using the mechanistic empirical

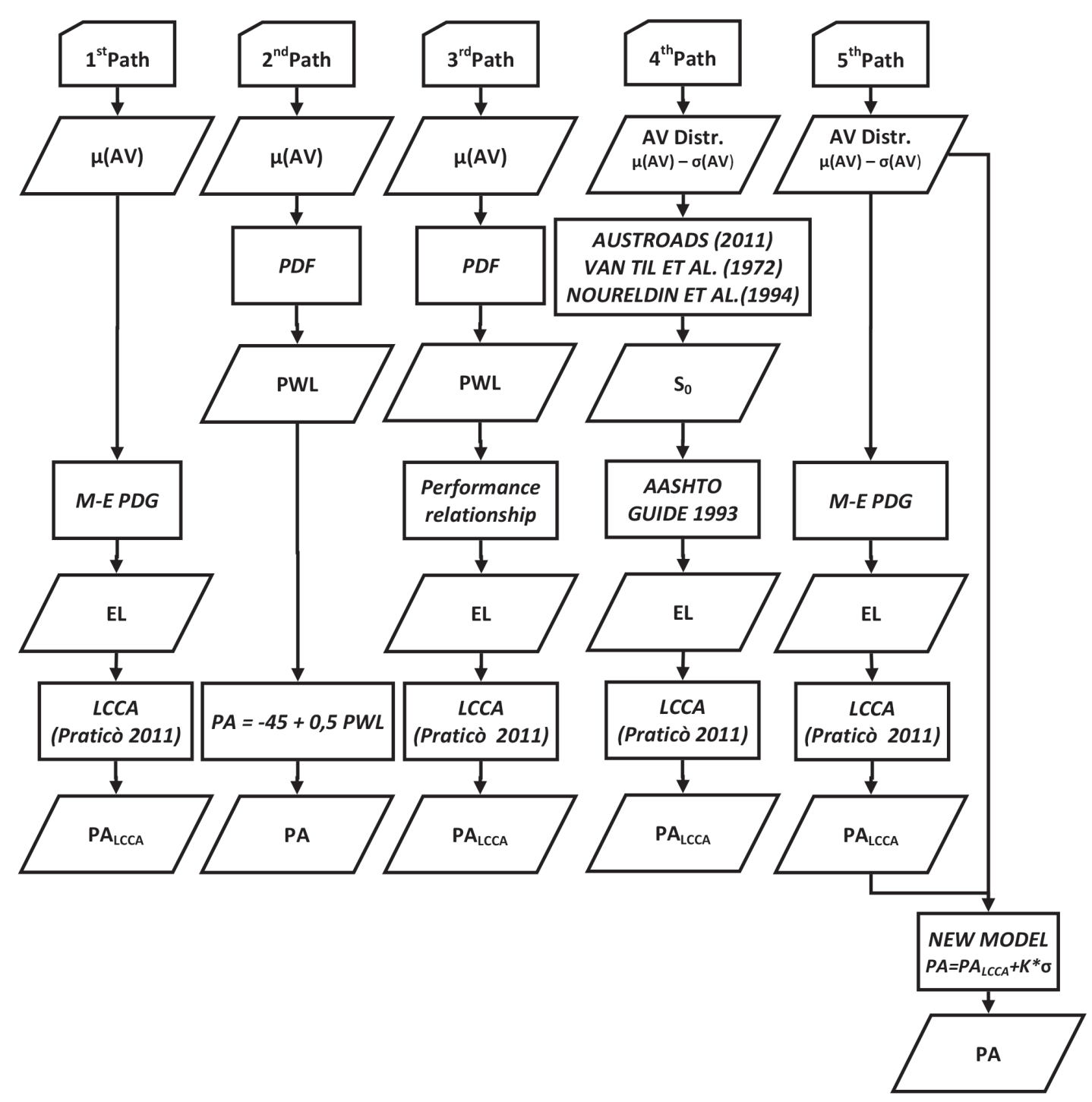

Fig. 1. Synapsis of the paper 
pavement design guide (M-E PDG), and the pay adjustment $\left(\mathrm{PA}_{\mathrm{LCCA}}\right)$ is derived based on a life cycle cost analysis (LCCA).

In the second case, a given probability density function (PDF) for the AV is assumed (average $\mu(\mathrm{AV})$, standard deviation $\sigma(\mathrm{AV}))$, and the percentage within limits $(\mathrm{PWL})$ is derived as a quality measure.

The PA is derived from the PWL based on a continuous payment schedule $(\mathrm{PA}=-45+0.5 \mathrm{PWL})$.

In the third case, once the PWL has been derived from the AV measure (based, as above, on a given PDF), the expected life of the pavement $(\mathrm{E})$ is derived from the PWL through a performance relationship. Subsequently, the PA is inferred from E, based on LCCA.

In the fourth path a given AV distribution is supposed. Different standard deviations and averages are considered in more detail. As a consequence, based on literature (Austroroads 2011), for each couple ( $\sigma(\mathrm{AV})$, $\mu(\mathrm{AV})$ ) the corresponding distributions of moduli and structural layer coefficients are derived. For each distribution of moduli there is a corresponding value of the overall variance $\mathrm{S}_{0}$ (AASHTO Guide 93). This fact allows the life expectancy of the pavement to be derived, under given hypotheses, through the AASHTO Guide 93 method (AASHTO 1993). Finally, the pay adjustment (PA) is derived by comparing the expected life of the as-constructed life vs. the expected life of the as-designed pavement. The fourth procedure focuses on AASHTO Guide, 1993 and its consequences in terms of material variance. In this paper only agency costs are considered.

In the fifth path, the probability density function of AV generates, through the M-EPDG (NCHRP 2004; Manika et al. 2012), different values of $E$. These values are interpreted through a linear model of PA as a function of the standard deviation of the process.

\subsection{New PA LCCA-based model}

This section deals with the formalization of a new model based on LCCA and on the consideration of the standard deviation of processes and materials. From a practical standpoint the new model can be divided into two parts: the first part (Pratico 2011) is based on LCCA and takes advantage from previous algorithms (Weed 2001; Praticò 2007; Praticò et al. 2011). The second part deals with a practical methodology which considers the relevance and the role of variance.

As for the first part of the model, all the previous LCCAbased models, under given hypotheses, can be simplified as in Eqn (1), where $\mathrm{PA}_{\text {old }}$ is the pay adjustment (the subscript is herein added), $\mathrm{R}$ is the ratio between $(1+\mathrm{i})$ and $(1+r)$, where $i$ is the inflation rate (typically 0.04$)$ and $\mathrm{r}$ is the interest rate (typically 0.08 ). D (for example, 20 years) is the expected life of the as-designed pavement (AD), E (for example 15 years) is the expected life of the as-constructed pavement (AC), $\mathrm{O}$ is the time between two successive rehabilitations or resurfacings (typically
10 years). Furthermore, let $C_{0}\left(€\right.$ or $\left.€ / \mathrm{m}^{2}\right)$ be the cost of the pavement at the time 0 and $\mathrm{C}$ the cost of rehabilitation at the given year. Then $\mathrm{C}_{0}$ and $\mathrm{C}$ can be identical:

$$
P A_{\text {old }}=C \cdot\left(R^{D}-R^{E}\right) \cdot\left(1-R^{O}\right)^{-1} .
$$

The as-designed pavement will need a rehabilitation after $\mathrm{D}$ years, after $2 \mathrm{D}$ years, etc. As a consequence the present value, $\mathrm{PV}$, of the total expenditures in $\mathrm{T}$ years (where $\mathrm{T}$ is the period of analysis, for example 50 years), will be as in Eqn (2), where $n \cdot \mathrm{D} \leq \mathrm{T}$, and $\mathrm{S}$ is the salvage value:

$$
P V_{A D T}=C_{0}+C \cdot \sum_{i=1}^{n} R^{i \cdot D}-S \cdot R^{T}
$$

If $\mathrm{T}$ tends to infinite, then Eqns (3)-(5) can be derived:

$$
\begin{gathered}
\lim _{n \rightarrow \infty} \sum_{i=1}^{n} R^{i \cdot D}=R^{D} \cdot\left(1-R^{D}\right)^{-1} ; \lim S=0 .(3), \\
P V_{A D}=\lim _{n \rightarrow \infty} P V_{A D T}=C_{0}+C \cdot R^{D} \cdot\left(1-R^{D}\right)^{-1} .
\end{gathered}
$$

The present value of $\mathrm{AC}$ and the pay adjustment (PA) result:

$$
\begin{gathered}
P V_{A C}=C_{0}+C \cdot R^{E} \cdot\left(1-R^{D}\right)^{-1} ; \\
P A=P V_{A D}-P V_{A C}=C \cdot\left(R^{D}-R^{E}\right) \cdot\left(1-R^{D}\right)^{-1} .
\end{gathered}
$$

Note that if $\mathrm{E}$ tends to $\mathrm{D}$, then $\mathrm{PA}$ tends to 0 , while if $\mathrm{E}$ tends to 0 , then PA tends to $-\mathrm{C}$ and the penalty (in absolute value) equals the cost. As for the resurfacings of $\mathrm{AD}$, they are scheduled at $\mathrm{O}, \mathrm{D}+\mathrm{O}, 2 \mathrm{D}+\mathrm{O}, \ldots$ In contrast, for the AC pavement, they are usually performed at $\mathrm{O}, \mathrm{E}+\mathrm{O}, \mathrm{E}+\mathrm{D}+\mathrm{O}, \mathrm{E}+2 \mathrm{D}+\mathrm{O}$, etc. The results are (where $\mathrm{F}=1$ when $\mathrm{E}>\mathrm{O}$, while $\mathrm{F}=0$ if $\mathrm{E} \leq \mathrm{O}$ and $\mathrm{O}<\mathrm{D})$ :

$$
\begin{gathered}
P V_{A D_{-} R E S}=C_{R E S} \cdot R^{O} \cdot\left[1+R^{D} \cdot\left(1-R^{D}\right)^{-1}\right] ; \\
P V_{A C_{-} R E S}=C_{R E S} \cdot R^{O} \cdot\left[F+R^{E} \cdot\left(1-R^{D}\right)^{-1}\right] ; \\
P A_{R E S}=C_{R E S} \cdot R^{O} \cdot\left[11-F+\left(R^{D}-R^{E}\right) \cdot\left(1-R^{D}\right)^{-1}\right] ; \\
P A+P A_{R E S}=C \cdot\left(R^{D}-R^{E}\right) \cdot\left(1-R^{D}\right)^{-1}+C_{R E S} \cdot R^{O} \\
{\left[1-F+\left(R^{D}-R^{E}\right) \cdot\left(1-R^{D}\right)^{-1}\right] .}
\end{gathered}
$$

Note that the above equations do not consider the standard deviation of the process/materials. The PA of Eqn (7) will be herein stated as $\mathrm{PA}_{\mathrm{LCCA}}$.

As for the second part of the model (see also the $5^{\text {th }}$ path below), the probability density functions describing the main quality characteristics (AV, thickness, asphalt 
binder content, etc.) determine the probability density function of the expected lives.

By splitting the pavement, under investigation, in $\mathrm{N}$ parts, it follows that:

$$
P A=\sum_{i=1}^{N} P A_{i}=\sum_{i=1}^{N} C_{i} \cdot P A_{i}^{*},
$$

where: $P A_{i}$ and $P A^{*}{ }_{i}$ (pay adjustments) and $E_{i}$ (expected life) refer to the $i$ th part of the pavement. It is supposed that (equal sections or parts under consideration).

It follows that:

$$
\frac{P A}{C_{i}}=\frac{P A \cdot N}{C}=\sum_{i=1}^{N} P A_{i}^{*},
$$

and

$$
\frac{P A}{C}=P A^{*}=\frac{\sum_{i=1}^{N} P A_{i}^{*}}{N},
$$

If $\sigma_{\mathrm{E}}$ indicates the standard deviation of $E$, then:

$$
\lim _{\sigma_{E} \rightarrow 0} \frac{P A}{c}=\frac{\sum_{i=1}^{N} P A_{i}^{*}}{N}=P A_{\mathrm{LCCA}}^{*},
$$

where PA* ${ }_{\text {LCCA }}$ is derived through Eqn (7) (where $\mathrm{PA}^{*}{ }_{\mathrm{LCCA}}$ stands for the ratio between PA in Eqn (7) and C). On the other hand, if $\sigma_{\mathrm{E}}$ results only from $\sigma_{\mathrm{AV}}$, that is, all defects arise from the air void content, and variations in the air void content affect the expected life, it can be easily seen that:

$$
\forall \sigma_{\mathrm{AV}}>0 \quad \mathrm{PA}^{*}<\mathrm{PA}_{\mathrm{LCCA}}^{*},
$$

and

$$
\mathrm{PA}^{*}=\mathrm{PA}_{\mathrm{LCCA}}^{*}+\mathrm{F}\left(\sigma_{\mathrm{AV}}\right)
$$

where F stands for function. A generalized algorithm can then be proposed:

$$
\mathrm{PA}^{*}=\mathrm{PA}_{\mathrm{LCCA}}^{*}+\mathrm{F}^{*}\left(\sigma_{\mathrm{AV}}, \sigma_{\mathrm{TH}}, \ldots .\right)
$$

where $\mathrm{F}^{*}$ is a function and $\sigma_{\mathrm{AV}}, \sigma_{\mathrm{TH}}$ are the standard deviations of the quality characteristics that can affect the expected life of the as-constructed pavement.

These fundamental Eqns (17) and (18) are intrinsically related to the nonlinearity of the $\mathrm{E} v s$. AV relationship. Apart from the relationship between $\mathrm{E}$ and $\mathrm{AV}$, the equations are consistent with: 1$)$ the need for homogeneous production; 2) an increase in the life cycle cost to increase the number of work zones (agency costs, etc.). Furthermore, the hypothesized normal distribution suggests that if the $\mu_{\mathrm{AV}}$ ranges from 4 to 8 and $\sigma_{\mathrm{AV}}$ ranges from 0 to 3 then:

$$
\mathrm{PA}^{*}=\mathrm{PA}_{\mathrm{LCCA}}^{*}-k \sigma_{\mathrm{AV}},
$$

where $k$ ranges from 2.3 to 4.7 and only accounts for an increase in the absolute value of the PA due to the peculiar assumptions under investigation (the normality of $\mathrm{AV}$, the derivation of $\mathrm{E}$ through the M-EPDG).

\subsection{First path}

In the first path, a multi-layered pavement has been considered for analysis. For each layer (friction course), thickness, material type, traffic (Russo, Musolino 2012), and annual climate statistics must be specified, as shown in Table 2.

The M-E PDG provides a conceptual and operational framework in order to design road pavements. The M-E PDG is used to derive an expected life (EL) corresponding to failure criteria (i.e. longitudinal cracking) for a given AV.

The following failure criteria must be considered (NCHRP 2004):

- Longitudinal cracking (ft/mi), defined as pavement cracking predominantly parallel to the direction of traffic;

- Alligator cracking (\%), defined as interconnected or interlaced cracks forming a pattern that resembles an alligator's hide. Also, map cracking;

- AC rutting (in), defined as asphalt concrete longitudinal depression or wearing away of the pavement in wheel paths under load;

- IRI, international roughness index (in/mi; baseline: 0.1mi, see Múčka, Granlund 2012), defined as a pavement roughness index computed from a longitudinal profile measurement using a quarter-car simulation at a speed of $50 \mathrm{mph}(80 \mathrm{Km} / \mathrm{h})$.

For a given AV, a minimum expected life (E) of the pavement is derived based on the minimum expected life for each criterion $(i=1,2 \ldots, 5)$ :

$$
\mathrm{E}=\min _{\mathrm{i}=1,2, \ldots \ldots, 5}(\mathrm{E})_{\mathrm{i}} .
$$

Finally, the pay adjustment is derived using Eqn (7).

\subsection{Second path}

In the $2^{\text {nd }}$ path, the first step (Fig. 1), the PDF describes the air void content, $\mathrm{f}(\mathrm{AV})$, for each average value of AV (Akkinepally, Attoh-Okine 2006; Burati, Weed 2006; Zaniewski, Hughes 2006; Wang et al. 2009; Katicha et al. 2011; Uddin et al. 2011). The PDF and cumulative distribution functions, $\mathrm{PCF}=\mathrm{f}(\mathrm{AV})$ for each average may be used to estimate the defect percentage, $\mathrm{PD}=100-\mathrm{PWL}$, for a given specification limit (Burati et al. 2003).

Once PD (or PWL) is estimated, the following continuous payment schedule can be defined:

$$
\mathrm{PA}^{*}=5-0.5 \cdot \mathrm{PD},
$$

where PA* indicates PA/C (\%). Note that Eqn (21) implies that:

$$
\begin{aligned}
& \mathrm{PA}^{*}=5-0.5 \cdot \mathrm{PD}=5-05 \cdot(100-\mathrm{PWL})= \\
& 5-50+0.5 \cdot \mathrm{PWL}=-45+0.5 \mathrm{PWL} .
\end{aligned}
$$


Table 2. Layer parameters and boundary conditions used to implement the M-E PDG

\begin{tabular}{|c|c|c|c|c|c|}
\hline \multicolumn{6}{|c|}{ Structural inputs } \\
\hline \multicolumn{3}{|c|}{ Layers 1 and 2 -Asphalt concrete } & \multicolumn{2}{|c|}{ Layer 3 - Granular base } & Layer 4 - Subgrade \\
\hline Material type: & $\mathrm{AC}$ & $\mathrm{AC}$ & UM & A-1-a & A-1-b \\
\hline $\mathrm{TH}$ & $\begin{array}{c}1.2 \mathrm{in.} \\
(30.5 \mathrm{~mm})\end{array}$ & $\begin{array}{c}1.8 \mathrm{in} . \\
(45.7 \mathrm{~mm})\end{array}$ & $\mathrm{TH}$ & $\begin{array}{l}11.8 \mathrm{in} . \\
(300 \mathrm{~mm})\end{array}$ & infinite \\
\hline \multicolumn{3}{|c|}{ Asphalt Mix (AM) } & \multicolumn{2}{|c|}{ Strength Properties } & Strength Properties \\
\hline $\mathrm{C} \% \mathrm{R}(3 / 4)$ & 0 & 0 & PR & 0.35 & 0.35 \\
\hline $\mathrm{C} \% \mathrm{R}(3 / 8)$ & 5 & 35 & $\mathrm{~K}_{0}$ & 0.5 & 0.5 \\
\hline $\mathrm{C} \% \mathrm{R}(\# 4)$ & 61 & 55 & MOD & $\begin{array}{l}30000 \mathrm{psi}(207 \text { MOD } \\
\mathrm{MPa})\end{array}$ & $\begin{array}{l}26500 \mathrm{psi} \\
(183 \mathrm{MPa})\end{array}$ \\
\hline$\% \mathrm{P}(\# 200)$ & 10 & 6 & \multirow{8}{*}{\multicolumn{3}{|c|}{$\begin{array}{l}\text { Notes: } 1 \text { in. }=25.4 \mathrm{~mm} ;{ }^{\circ} \mathrm{C}=\left({ }^{\circ} \mathrm{F}-32\right) \cdot 5 / 9 ; 1 \mathrm{psi} \cong 0.0068 \mathrm{MPa} \\
1 \mathrm{pcf} \cong 0.157 \mathrm{kN} / \mathrm{m}^{3} ; 3 / 4 \mathrm{in} . \cong 19 \mathrm{~mm} ; 3 / 8 \mathrm{in} . \cong 9.5 \mathrm{~mm} ; \\
\# 4 \rightarrow 4.75 \mathrm{~mm} ; \# 200 \rightarrow 0.075 \mathrm{~mm} . \\
\text { Symbols: } \mathrm{AC}=\text { asphalt concrete; } \mathrm{UM}=\text { unbound material; } \\
\mathrm{TH}=\text { thickness; } \mathrm{C} \% \mathrm{R}(3 / 4)=\text { cumulative } \% \text { retained in the } \\
\text { given } 3 / 4 \text { sieve; } \% \mathrm{P}(\# 200)=\% \text { passing } \# 200 \text { sieve; } \\
\text { Pen = penetration grade }(0.1 \mathrm{~mm}) ; \mathrm{TR}=\text { reference temperature; } \\
\mathrm{B} \%=\text { effective binder content }(\text { volume, } \%) \\
\mathrm{UW}=\text { total unit weight; } \mathrm{PR}=\text { Poisson's ratio; } \\
\mathrm{K}_{0}=\text { Coefficient of lateral pressure; MOD = modulus. }\end{array}$}} \\
\hline \multicolumn{3}{|c|}{ Asphalt Binder $(A B)$} & & & \\
\hline Pen & $60-70$ & $85-100$ & & & \\
\hline \multicolumn{3}{|c|}{ General Properties $(G P)$} & & & \\
\hline TR & \multicolumn{2}{|c|}{$70{ }^{\circ} \mathrm{F}\left(21^{\circ} \mathrm{C}\right)$} & & & \\
\hline $\mathrm{B} \%$ & \multicolumn{2}{|c|}{11} & & & \\
\hline UW & \multicolumn{2}{|c|}{148 pcf $\left(23.2 \mathrm{kN} / \mathrm{m}^{3}\right)$} & & & \\
\hline PR & \multicolumn{2}{|c|}{0.35} & & & \\
\hline \multicolumn{6}{|l|}{ Traffic inputs } \\
\hline \multicolumn{6}{|c|}{$\begin{array}{l}\text { Initial two-way AADTT: 1450; Number of lanes in the design direction: } 2 \text {; Percentage of trucks in the design direction: } 50 \% \text {; } \\
\text { Percentage of trucks in the design lane: } 95 \% \text {; Operational speed: } 60 \mathrm{mph}(96.5 \mathrm{~km} / \mathrm{h}) \text {. }\end{array}$} \\
\hline \multicolumn{6}{|c|}{ Annual climate statistics } \\
\hline \multicolumn{6}{|c|}{$\begin{array}{l}\text { mean annual air temperature: } 62.12^{\circ} \mathrm{F}\left(16.7^{\circ} \mathrm{C}\right) \text {; mean annual rainfall: } 14.17 \mathrm{in} .(360 \mathrm{~mm}) \text {; freezing index: } 0.17^{\circ} \mathrm{F} \text {-days; } \\
\text { average annual number of freeze/thaw cycles: } 0 \text {. }\end{array}$} \\
\hline \multicolumn{6}{|c|}{ Performance criteria failure mechanism limit } \\
\hline \multicolumn{6}{|c|}{$\begin{array}{l}\text { AC surface down cracking: } 2000 \mathrm{ft} / \mathrm{mi}(380 \mathrm{~m} / \mathrm{km}) \text {; AC bottom up cracking: } 25 \% \text {; AC permanent deformation: } 0.25 \mathrm{in} .(6.4 \\
\mathrm{mm}) \text {; total permanent deformation: } 0.75 \mathrm{in}(19 \mathrm{~mm}) \text {; terminal IRI: } 172 \mathrm{in} / \mathrm{mi}(2.7 \mathrm{~mm} / \mathrm{m}) \text {. }\end{array}$} \\
\hline
\end{tabular}

It follows that:

$\mathrm{PF}=100+\mathrm{PA}^{*}=100-45+0.5 \mathrm{PWL}=55+0.5 \mathrm{PWL}$,

where PF is the pay factor. This result yields the acceptance quality level (AQL), which is the minimum PWL for which $\mathrm{PA}=0$ is $90 \%$.

\subsection{Third path}

In the third logical path, a PWL (percentage within limits) is derived for each AV (under the abovementioned probability distribution hypotheses). Additionally, for each PWL, a PD (defect percentage) is derived. In this case, the performance relationship $\mathrm{E}\left(\mathrm{PD}_{\mathrm{i}}\right)$ can be described by a polynomial performance model (Burati et al. 2003), i.e. expected life as function of defect percentage:

$\mathrm{E}=22.9-0.163 \cdot \mathrm{PD}_{\mathrm{AV}}-0.135 \mathrm{PD}_{\mathrm{TH}}+0.000961 \cdot \mathrm{PD}_{\mathrm{TH}}$,

where $\mathrm{PD}_{\mathrm{AV}}$ and $\mathrm{PD}_{\mathrm{TH}}$ respectively stand for the air void and thickness defect percentage. It is noted that the thickness defect percentage is assumed to be $10 \%$, as in (Burati et al. 2003). Equation (24) yields an expected life of $\mathrm{E}=20$ years for $\mathrm{PD}_{\mathrm{AV}}=\mathrm{PD}_{\mathrm{TH}}=10$, and $\mathrm{E}=5$ years for $\mathrm{PD}_{\mathrm{AV}}=75$ and $\mathrm{PD}_{\mathrm{TH}}=90$. Finally, the pay adjustment is estimated.

\subsection{Fourth path}

In the fourth path (Fig. 2), based on AV distribution, the distribution of the layer modulus is derived (Austroads 2011). Based on mechanical properties and their statistics, it is possible to estimate the variance in pavement performance prediction $\left(\mathrm{S}_{\mathrm{N}}{ }^{2}\right)$ and the overall standard deviation $\left(\mathrm{S}_{0}\right)$ (Noureldin et al. 1994). For each AV distribution, an estimate of the expected life, is derived according to the AASHTO Guide 1993 and, finally, an estimate of the pay adjustment.

It is noted that AV variability generates modulus variability and this latter causes the variability of Marshall Stability, which is the input of Noureldin Model (Noureldin et al. 1994). The factor $\mathrm{S}_{0}$ in the AASHTO 1993 Algorithm (AASHTO 1993) is consequently modified.

Under these assumptions the expected life (E) associated to each couple ( $\mu(\mathrm{AV}), \sigma(\mathrm{AV}))$ is derived and the pay adjustment is estimated by using Eqn (7). 


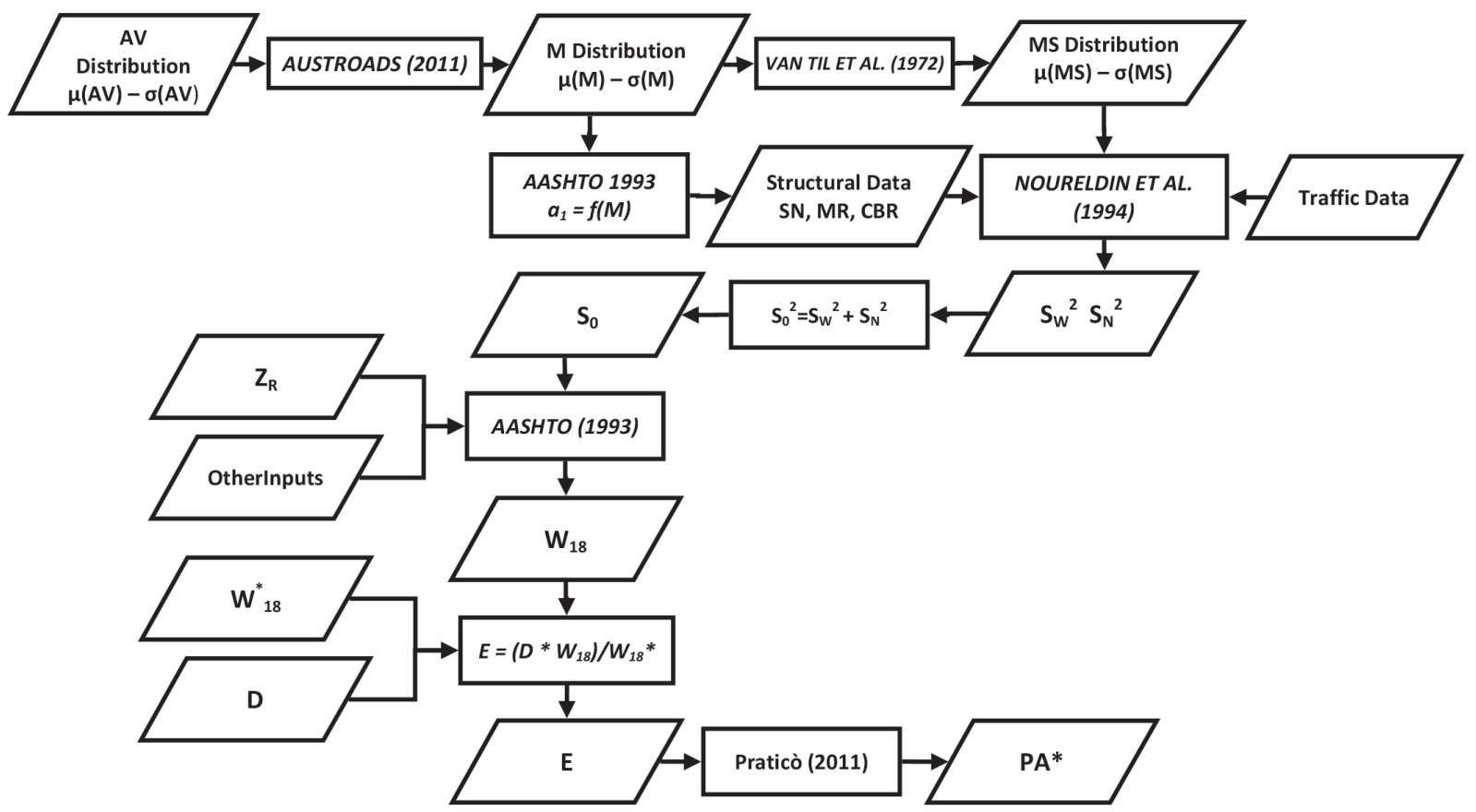

Notes:

$A V=$ Air Voids (\%), $M=$ Modulus (psi), MS = Marshall Stability (lb), $a_{1}=$ Structural Layer Coefficient,

$S N=$ Structural Number, $M R=$ Subgrade Resilient Modulus (psi),$C B R=$ California Bearing Ratio (\%),

$S^{2}{ }_{W}=$ Variance in Traffic prediction, $S^{2}{ }_{N}=$ Variance in Pavement Performance prediction, $S^{2}{ }_{0}=$ Overall Variance,

$S_{0}=$ Overall Std. Deviation, $Z_{R}=$ Std. Normal Deviate, $W_{18}=$ predicted number of $18.000 \mathrm{lb}$ ESALs,

$D=$ Design Life (Years), $W_{18}^{*}=$ number of $18.000 \mathrm{lb}$ ESALs corresponding to D, E = Expected Life (Years),

$P A^{*}=$ Pay Adjustment/cost (\%).

Fig. 2. Fourth path used to derive PA - flowchart

\subsection{Fifth path (new model)}

In the $5^{\text {th }}$ path, it was assumed that the probability density functions describing the main quality characteristics (AV, thickness, asphalt binder content, etc.) determine the PDF of the expected lives.

It is assumed that $\sigma_{\mathrm{EL}}$ results only from $\sigma_{\mathrm{AV}}$, that is, that all defects arise from the air void content, and variations in the air void content affect the expected life.

So the values of pay adjustment derived through the $1^{\text {st }}$ path $\left(\mathrm{PA}^{*}{ }_{\text {LCCA }}\right)$ are corrected by Eqn (19) (in which $k=2.3$ ) in order to account variability in air void content.

This path refers to the application of the model set out in Section 1.2.

\section{Results}

Tables 3 to 10 and Figure 3 summarize results.

$1^{\text {st }}$ path

Based on the conceptual framework described above, the air void content $\left(A V_{m}\right.$, where $A V_{m}$ stands for $\left.\mu(A V)\right)$ is assumed to vary from $5 \%$ to $11 \%$, as described in Table 3 (a value of $11-12 \%$ is usually referred to as acceptance limit, Seebaly and Bazi (2005)).

Table 3 also lists the expected lives $\mathrm{E}_{\mathrm{i}}$ (months) obtained through the application of the MEPDG reported for each failure criterion for a given $\mathrm{AV}_{\mathrm{m}}$.

The expected life of the as-designed pavement, D, is assumed to correspond to $\mathrm{AV}=5 \%$, whereas $\mathrm{E}$, the

Table 3. Minimum expected life for different failure criteria

\begin{tabular}{ccccccc}
\hline & \multicolumn{3}{c}{$\mathrm{E}_{\mathrm{i}}$ (months) } & & $\begin{array}{c}\mathrm{E} \\
\text { minimum } \\
\text { (months) }\end{array}$ \\
\hline $\begin{array}{c}\mathrm{AV} \\
(\%)\end{array}$ & $\begin{array}{c}\text { Longi- } \\
\text { tudinal }\end{array}$ & $\begin{array}{c}\text { Alli- } \\
\text { gator }\end{array}$ & $\begin{array}{c}\text { Rutting } \\
\text { AC }\end{array}$ & $\begin{array}{c}\text { Total } \\
\text { Rutting }\end{array}$ & IRI & Min. E \\
\hline 5 & 395 & 549 & 240 & 288 & 638 & 240 \\
\hline 8 & 178 & 222 & 189 & 212 & 445 & 178 \\
\hline 11 & 91 & 94 & 129 & 202 & 249 & 91 \\
\hline
\end{tabular}

expected life of the as-constructed pavement, is derived from Table 3 as a function of the air void content.

Table 4 summarizes the main inputs used and the pay adjustments obtained (see Eqns (1) and (7)).

Note that in this case, PA/C ranges from $-53 \%$ (11 vs. $5 \%$ ) to $0 \%$ (process completely under control in terms of the mean). Despite this appreciable difference, in both cases ( $\mathrm{AV}=5 \%$ and $\mathrm{AV}=11 \%)$, half the population has values greater than the average of an unknown quantity, depending on the standard deviation. On the other hand, regardless of the distribution, for a given $\mathrm{AV}_{\mathrm{m}}$ (for example $8 \%$ ), high $\sigma$ implies that a considerable part of the pavement is characterized by $\mathrm{AV}<\mathrm{AV}_{\mathrm{m}}$, and a considerable part of the pavement has $A V>A V_{m}$. Higher values of $\sigma$ would require rehabilitation across areas in which high and low values coexist. This conclusion reflects the fact that $\sigma_{\mathrm{AV}}$ contains essential information not included in $\mathrm{AV}_{\mathrm{m}}$. 
Table 4. Pay adjustment ( $1^{\text {st }}$ path)

\begin{tabular}{lccccccc}
\hline $\begin{array}{c}\mathrm{AV} \\
(\%)\end{array}$ & INT & INF & R & $\begin{array}{c}\mathrm{D} \\
\text { (Years) }\end{array}$ & $\begin{array}{c}\mathrm{E} \\
(\text { Years })\end{array}$ & $\begin{array}{c}\text { PA* OLD } \\
(\text { Eqn (1)) }\end{array}$ & $\begin{array}{c}\text { PA* } \\
(\text { Eqn (7)) }\end{array}$ \\
\hline $\mathbf{5}$ & 0.08 & 0.04 & 0.962963 & 20 & 20.00 & $\mathbf{0 . 0 0 \%}$ & $\mathbf{0 . 0 0 \%}$ \\
\hline $\mathbf{8}$ & 0.08 & 0.04 & 0.962963 & 20 & 14.81 & $\mathbf{- 3 2 . 0 0 \%}$ & $-\mathbf{- 1 9 . 0 2 \%}$ \\
\hline $\mathbf{1 1}$ & 0.08 & 0.04 & 0.962963 & 20 & 7.56 & $\mathbf{- 8 9 . 2 3 \%}$ & $\mathbf{- 5 3 . 0 4 \%}$ \\
\hline
\end{tabular}

Table 5. Pay adjustment (2nd path)

\begin{tabular}{lcccccc}
\hline & \multicolumn{3}{c}{$\mathrm{PD}(\%)$} & \multicolumn{3}{c}{$\mathrm{PA}(\%)$} \\
\hline $\mathrm{AV} \mathrm{( \% )}$ & $\begin{array}{c}\sigma_{\mathrm{AV}}= \\
0.5\end{array}$ & $\begin{array}{c}\sigma_{\mathrm{AV}}= \\
2.4\end{array}$ & $\sigma_{\mathrm{AV}}=3$ & $\sigma_{\mathrm{AV}}=$ & $\sigma_{\mathrm{AV}}=$ & $\sigma_{\mathrm{AV}}=3$ \\
& 0 & 10 & 16 & $\mathbf{5 . 0 0}$ & $\mathbf{0 . 0 0}$ & $\mathbf{- 2 . 9 3}$ \\
\hline $\mathbf{5}$ & 50 & 50 & 50 & $\mathbf{- 2 0 . 0 0}$ & $\mathbf{- 2 0 . 0 0}$ & $\mathbf{- 2 0 . 0 0}$ \\
\hline $\mathbf{8}$ & 100 & 90 & 84 & $\mathbf{- 4 5 . 0 0}$ & $\mathbf{- 4 0 . 0 0}$ & $\mathbf{- 3 7 . 0 7}$ \\
\hline $\mathbf{1 1}$ & & & & & &
\end{tabular}

\section{$2^{\text {nd }}$ path}

In the second path, a Gaussian probability density function is assumed for each average value $(5,8,11 \%)$ and for three different values of standard deviation $(\sigma=$ $0.5,2.4,3 \%)$. This range has been chosen based on a survey of literature data (Hughes 1996; Katicha et al. 2010).

Based on Eqns (21)-(22), PA is derived as in Table 5. $3^{\text {rd }}$ path

In the third case, for each $\mathrm{AV}$ and $\sigma_{\mathrm{AV}}$, a PWL is derived, again based on a Gaussian PDF. From PWLs, PDs, are derived (Table 6).

Table 6 summarizes the values of E corresponding to each $\mathrm{AV}$ and $\sigma_{\mathrm{AV}}$. The values of $\mathrm{E}$ are used to estimate PA using the algorithms described above (Weed 2001; Praticò 2007, 2011). Table 7 summarizes the obtained results. Larger differences in the as-designed AV (5\%) and the as-constructed AV (11\%) produce higher PDs and, therefore, lower pay factors. Note that the empirical nature of the method can lead to criticism that illogical or inconsistent results may be obtained (for example, if nonconformities refer to other quality characteristics, or if the design life is not 20 years).

The standard deviation strongly affects the results of the second and third path due to the dependence of PWL (or PD) on $\sigma$ (standard deviation) for a given quality characteristic. This interaction can also affect the potential assumption of violation normality. Based on these assertions, the following observations may be made:

- the LCCA-based method ( $1^{\text {st }}$ path) is partly inconsistent because it does not depend on the dispersion (variability) of the quality characteristics;

- the PD-based methods ( $2^{\text {nd }}$ and $3^{\text {rd }}$ paths) are intrinsically empirical due to a lack of well-grounded links between PA and the expected life.
Table 6. Expected life ( $3^{\text {rd }}$ Path)

\begin{tabular}{|c|c|c|c|c|c|c|c|}
\hline & \multicolumn{3}{|c|}{ PD (\%) } & \multirow{2}{*}{$\begin{array}{c}\mathrm{PD}_{\mathrm{TH}} \\
(\%)\end{array}$} & \multicolumn{3}{|c|}{ E (years) } \\
\hline $\begin{array}{l}\mathrm{AV} \\
(\%)\end{array}$ & $\begin{array}{c}\sigma_{\mathrm{AV}}= \\
0.5\end{array}$ & $\begin{array}{c}\sigma_{\mathrm{AV}} \\
=2.4\end{array}$ & $\begin{array}{l}\sigma_{\mathrm{AV}} \\
=3\end{array}$ & & $\begin{array}{c}\sigma_{\mathrm{AV}}= \\
0.5\end{array}$ & $\begin{array}{c}\sigma_{\mathrm{AV}}= \\
2.4\end{array}$ & $\begin{array}{l}\sigma_{\mathrm{AV}} \\
=3\end{array}$ \\
\hline 5 & 0 & 10 & 16 & 10 & 21.55 & 20.02 & 19.12 \\
\hline 8 & 50 & 50 & 50 & 10 & 13.88 & 13.88 & 13.88 \\
\hline 11 & 100 & 90 & 84 & 10 & 6.21 & 7.74 & 8.64 \\
\hline
\end{tabular}

Consequently, an excess of variability in the layer quality characteristics would not provide variable pay adjustment in the first class of methods because the averages of the main quality characteristics are unchanged. Similarly, pavement with a higher expected life can correspond to a lower pay factor in the second class of methods. In summary, both classes of methods lead to questionable conclusions.

$4^{\text {th }}$ path

For each AV distribution (1st and 2nd columns in Table 8) an estimate of the expected life is derived (penultimate column in Table 8) according to the AASHTO Guide (1993) and, finally, an estimate of the pay adjustment.

The above table shows how the factor $S_{0}$ and the expected life (E) of the pavement vary in function in a standard deviation of the air void content (AV). Higher sigmas yield lower expected lives and consequently higher values of the pay adjustment, especially when high values of the air void content are considered.

$5^{\text {th }}$ path

The results obtained for the fifth path (i.e. the proposed method) are reported in Table 9.

Eqn (1), Eqn (7) and Eqn (19) show the same trend but only Eqn (19) permits the synergetic consideration of location and dispersion indicators of expected life. Furthermore, being based on expected life and LCCA, they allow for consideration of innovative and/ or premium pavements and surfaces (Chen et al. 2011; Hoyos et al. 2011; Romanoschi et al. 2004, Praticò et al. 2010).

\subsection{Comparison}

To compare the models, a wide range of AV values (4 11) was considered. The standard deviation has been varied over the range $0.5-3$.

Figure 3 illustrates the dependence of PA* (pay adjustment/cost) on $\mathrm{AV}_{\mathrm{m}}$ for the five selected algorithms.

Finally, Table 10 summarizes the dependence of $\mathrm{PA}^{*}$ on method and data (mean and standard deviation, $\mathrm{k}=2.3$ ).

The first path (and its related fifth path, the proposed model) fit the remaining models for AV lower than approximately $6 \%$. In contrast, the $1^{\text {st }}$ and $3^{\text {rd }}$ paths yielded similar behaviour for AV values higher than 
Table 7. Pay adjustment (3rd Path)

\begin{tabular}{|c|c|c|c|c|c|c|c|c|c|c|c|}
\hline \multirow{3}{*}{$\begin{array}{l}\text { AV } \\
(\%)\end{array}$} & \multirow{3}{*}{$\begin{array}{c}\text { D } \\
\text { (Years) }\end{array}$} & \multicolumn{3}{|c|}{ E (Years) } & \multirow{3}{*}{$\begin{array}{c}\mathrm{O} \\
\text { (Years) }\end{array}$} & \multicolumn{3}{|c|}{$\begin{array}{l}\text { PA* } \text { OLD }(\%) \\
(\operatorname{Eqn}(1))\end{array}$} & \multicolumn{3}{|c|}{$\begin{array}{l}\text { PA* }(\%) \\
(\operatorname{Eqn}(7))\end{array}$} \\
\hline & & \multicolumn{3}{|c|}{$\sigma_{\mathrm{AV}}$} & & \multicolumn{3}{|c|}{$\sigma_{\mathrm{AV}}$} & \multicolumn{3}{|c|}{$\sigma_{\mathrm{AV}}$} \\
\hline & & 0.5 & 2.4 & 3 & & 0.5 & 2.4 & 3 & 0.5 & 2.4 & 3 \\
\hline 5 & 20 & 21.55 & 20.02 & 19.12 & 10 & 8.50 & 0.09 & $-\mathbf{5 . 0 7}$ & 5.04 & 0.05 & -3.01 \\
\hline 8 & 20 & 13.88 & 13.88 & 13.88 & 10 & -38.85 & -38.85 & -38.85 & -23.05 & -23.05 & -23.05 \\
\hline 11 & 20 & 6.21 & 7.74 & 8.64 & 10 & -102.9 & -87.94 & -80.01 & -60.57 & -52.17 & -47.47 \\
\hline
\end{tabular}

Table 8. Pay adjustment (4th Path)

\begin{tabular}{|c|c|c|c|c|c|c|c|c|c|c|c|c|}
\hline $\begin{array}{l}\text { AV } \\
(\%)\end{array}$ & $\sigma_{\mathrm{AV}}$ & $\mathrm{S}_{\mathrm{W}}^{2}$ & $\mathrm{~S}_{\mathrm{N}}^{2}$ & $\mathrm{~S}_{0}^{2}$ & $\mathrm{~S}_{0}$ & $\begin{array}{c}Z_{R} \\
(95 \%)\end{array}$ & $\mathrm{S}_{0} * \mathrm{Z}_{\mathrm{R}}$ & $\mathrm{W}_{18}$ & $\mathrm{~W}_{18} *$ & $\begin{array}{c}\mathrm{E} \\
\text { (years) }\end{array}$ & $\begin{array}{c}\text { PA* }^{*}(\%) \\
(\operatorname{Eqn}(1))\end{array}$ & $\begin{array}{l}\mathrm{PA}^{*}(\%) \\
(\operatorname{Eqn}(7))\end{array}$ \\
\hline \multirow{4}{*}{5} & 0.71 & \multirow{4}{*}{0.03} & 0.0721 & 0.1021 & 0.3196 & \multirow{4}{*}{-1.645} & -0.526 & 433,624 & \multirow{4}{*}{418,123} & 20.74 & 4.13 & 2.45 \\
\hline & 1.15 & & 0.0784 & 0.1084 & 0.3292 & & -0.542 & 418,123 & & 20.00 & 0.00 & 0.00 \\
\hline & 2.00 & & 0.0975 & 0.1275 & 0.3571 & & -0.587 & 376,236 & & 18.00 & -11.75 & -6.97 \\
\hline & 3.00 & & 0.1318 & 0.1618 & 0.4023 & & -0.662 & 317,016 & & 15.16 & -29.96 & -17.77 \\
\hline \multirow{4}{*}{8} & 0.71 & & 0.0699 & 0.0999 & 0.3161 & \multirow{4}{*}{-1.645} & -0.520 & 312,676 & \multirow{4}{*}{418,123} & 14.96 & -31.37 & -18.61 \\
\hline & 1.15 & & 0.0736 & 0.1036 & 0.3219 & & -0.530 & 305,819 & & 14.63 & -33.63 & -19.95 \\
\hline & 2.00 & 0.03 & 0.0852 & 0.1152 & 0.3394 & & -0.558 & 286,181 & & 13.69 & -40.24 & -23.87 \\
\hline & 3.00 & & 0.1073 & 0.1373 & 0.3706 & & -0.610 & 254,370 & & 12.17 & -51.46 & -30.52 \\
\hline \multirow{4}{*}{11} & 0.71 & \multirow{4}{*}{0.03} & 0.0701 & 0.1001 & 0.3164 & \multirow{4}{*}{-1.645} & -0.520 & 181,827 & \multirow{4}{*}{418,123} & 8.70 & -79.58 & -47.21 \\
\hline & 1.15 & & 0.0741 & 0.1041 & 0.3227 & & -0.531 & 177,504 & & 8.49 & -81.38 & -48.27 \\
\hline & 2.00 & & 0.0877 & 0.1177 & 0.3431 & & -0.564 & 164,296 & & 7.86 & -86.95 & -51.58 \\
\hline & 3.00 & & 0.2253 & 0.2553 & 0.5053 & & -0.831 & 88,886 & & 4.25 & -121.44 & -72.03 \\
\hline
\end{tabular}

Symbols: see Figure 2

Table 9. Pay adjustment (5th Path)

\begin{tabular}{|c|c|c|c|c|c|}
\hline \multirow[t]{2}{*}{$\begin{array}{l}\text { AV } \\
(\%)\end{array}$} & \multirow[t]{2}{*}{$\begin{array}{c}\mathrm{PA}^{*}{ }_{\text {old }}(\%) \\
(\operatorname{Eqn}(1))\end{array}$} & \multirow[t]{2}{*}{$\begin{array}{c}\mathrm{PA}^{*} \mathrm{LCCA} \\
(\%) \\
(\operatorname{Eqn}(7))\end{array}$} & \multirow[t]{2}{*}{$\mathrm{k}$} & \multicolumn{2}{|c|}{$\begin{array}{c}\text { PA* }(\%) \\
\text { New Model (Eqn (19)) } \\
\left(\mathrm{PA}^{*}=\mathrm{PA}^{*}{ }_{\mathrm{LCCA}}^{-}\right. \\
\left.\mathrm{k} \cdot \sigma_{\mathrm{AV}}\right)\end{array}$} \\
\hline & & & & $\sigma_{\mathrm{AV}}=0.5$ & $\sigma_{\mathrm{AV}}=3$ \\
\hline 5 & $0.00 \%$ & $0.00 \%$ & \multirow{3}{*}{2.3} & -1.15 & -6.90 \\
\hline 8 & $-32.00 \%$ & $-19.02 \%$ & & -20.17 & -25.92 \\
\hline 11 & $-89.23 \%$ & $-53.04 \%$ & & -54.19 & -59.94 \\
\hline
\end{tabular}

Note: Eqn (19) contains Eqn (7)

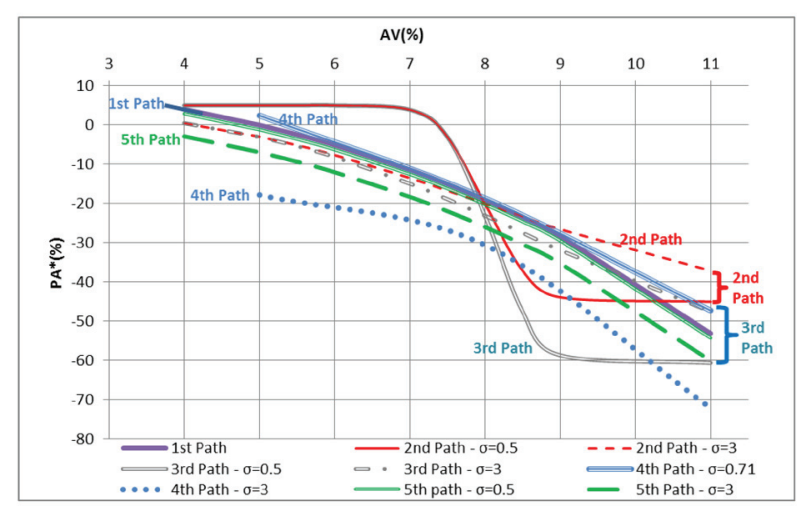

Fig. 3. $\mathrm{PA}^{*}$ as a function of $\mathrm{AV}$ (1st to 5th path)
Table 10. PA*, synthesis

\begin{tabular}{llllll}
\hline \multicolumn{1}{c}{ Path } & AV (\%) & $\sigma(\mathrm{AV})$ & $\begin{array}{c}\mathrm{E} \\
(\text { years })\end{array}$ & $\begin{array}{c}\mathrm{PA}^{*} \text { old } \\
(\text { Eqn }(1))\end{array}$ & $\begin{array}{c}\mathrm{PA}^{*} \\
(\text { Eqn }(7))\end{array}$ \\
\hline $1^{\text {st }}$ & $4 \sim 11$ & - & $7.5 \sim 21$ & $-89 \sim 6.8$ & $-53 \sim 4$ \\
\hline $2^{\text {nd }}$ & & & & & \\
{$[\mathrm{PA}=$} & $4 \sim 11$ & $0.5-3$ & - & $-45 \sim 5$ & - \\
$\mathrm{f}(\mathrm{PWL})]$ & & & & & \\
\hline $3^{\text {rd }}$ & $4 \sim 11$ & $0.5-3$ & $6 \sim 21.5$ & $-102 \sim 8.5$ & $-60 \sim 5$ \\
\hline $4^{\text {th }}$ & $5-8-11$ & $0.7-3$ & $4 \sim 20.7$ & $-121 \sim 4$ & $-72 \sim 2.5$ \\
\hline $5^{\text {th }}$ & & & & & \\
$($ New & $4 \sim 11$ & $0.5-3$ & - & $-96 \sim 5.7$ & $-60 \sim 3$ \\
Model, & & & & & \\
Eqn (19)) & & & & & \\
\hline
\end{tabular}

approximately $8 \%$. By referring to values that might be expected in practice, it is noted that the convergence of the different models for medium-to-high AV ( 7-9\%) and medium-to-high $\sigma(\sim 1-2)$, where there is evidence of recurring issues for road agencies (Vazquez et al. 2009).

\section{Main findings}

Pavement design, construction, quality assurance and control often follow different conceptual frameworks. This paper presents the formalization and validation of a model to determine a pay adjustment on the basis of 
mechanical and functional performance of transportation infrastructures. A model to determine a pay adjustment based on the expected life of the pavement and the variability of its main properties was formulated.

The dependence of pay adjustment on the acceptance procedures and pavement quality was analyzed. Under the hypotheses described above, the LCCA-based $3^{\text {rd }}$ approach and the purely empirical $2^{\text {nd }}$ approach yield similar results for small values of AV and small $\sigma$. In contrast, they diverge for high values of AV and high $\sigma$. The LCCA-based $1^{\text {st }}$ approach correlates well with the LCCA-based $3^{\text {rd }}$ approach only for high AV and low $\sigma$. These results agree with those derived from the $2^{\text {nd }}$ path but for only low $\mathrm{AV}$ and low $\sigma$.

The weak points of the LCCA-based and PD-based models are analysed and discussed, and a new model is proposed. The new model features the advantages of the LCCA-based model without neglecting the relevance of process variability (in terms of standard deviation).

In the model set out, compensatory characteristics and variability issues are synergistically addressed under the framework of life cycle cost analysis.

Although more research is needed, analyses prove that the new model is able to provide a solution which is well grounded in logic, even in cases where characteristics such as air void content, thickness, drainability or friction are defective and a premature failure is expected. In the new algorithm, the penalty-to-cost ratio doesn't assume values lower than -1 , which agrees with common logic.

The model developed here may be applied toward a variety of applications and may link design processes with construction performance and solutions. The use of algorithms for predicting the expected life of a pavement may be easily implemented as part of the model proposed here.

The main application of this model is in the field of quality assurance for porous asphalt concretes and sustainable infrastructures, the price of which can be consistently higher than that, such traditional dense-graded friction courses. Future developments of the model may well emerge in the field of life expectancy estimates for functional performance.

\section{Acknowledgment}

The authors would like to acknowledge Dr Richard Weed for the insightful suggestions.

\section{References}

AASHTO. 1993. AASHTO Guide for Design of Pavement Structures. Washington D.C.: American Association of State Highway and Transportation Officials. 640 p.

Aguiar-Moya, J. P.; Prozzi, J. A. 2011. Effect of field variability of design inputs on the MEPDG, in Transportation Research Board 90 ${ }^{\text {th }}$ Annual Meeting, 23-27 January, 2011, Washington, D.C.

Akkinepally, R.; Attoh-Okine, N. 2006. Quality control and quality assurance of hot mix asphalt construction in delaware. Department of Civil and Environmental Engineering, University of Delaware, Delaware Center for Transportation. $136 \mathrm{p}$.

Arafah, A. M. 1997. Reliability of flexible highway pavement system in Saudi Arabia. Civil Engineering Department, College of Engineering, King Saud University, Riyadh, Saudi Arabia. 12 p.

Attoh-Okine, N.O.; Kim, W.M. 1994. Pavement thickness variability and its effect on determination of moduli and remaining life, Transportation Research Record 1449: 39-44.

Austroads. 2011. The influence of compaction on the performance of dense graded asphalt. Technical Report APT194-11.

Boscaino, G.; Celauro, B.; Celauro, C.; Amadore, A. 2009. Evaluation of the laboratory prediction of surface properties of bituminous mixtures, Construction and Building Materials 23(2): 943-952.

http://dx.doi.org/10.1016/j.conbuildmat.2008.05.006

Boscaino, G.; Praticò, F.G. 2001. A classification of surface texture indices of pavement surfaces, Bulletin des Laboratoires des Ponts et Chaussees, September 234: 17-34.

Burati, J. L.; Weed, R. M. 2006. Accuracy and precision of typical quality measures, Transportation Research Record: Journal of the Transportation Research Board 1946: 71-81.

Burati, J. L.; Weed, R. M.; Hughes, C. S.; Hill, H. S. 2003. Optimal procedures for quality assurance specifications, FHWA report FHWA-RD-02-095.

Carvalho, R. L. 2006. Mechanistic-empirical design of flexible pavements: a sensitivity study. Master of Science Thesis, University of Maryland, USA.

Chen, M.; Lin, J.; Wu, S. 2011. Potential of recycled fine aggregates powder as filler in asphalt mixture, Construction and Building Materials 25(10): 3909-3914. http://dx.doi.org/10.1016/j.conbuildmat.2011.04.022

D’Apuzzo, M.; Nicolosi, V. 2010. A new methodology for stochastic modelling of pay factors in hot-mix asphalt pavements, Road Materials and Pavement Design 11 (supplement): 559-585.

Darter, M. I.; Hudson, W. R.; Brown, J. L. 1973. Statistical variations of flexible pavement properties and their considerations in design, Proceedings Annual Meeting of the Association of Asphalt Pavement Technologists 42: 589-613.

Gedafa, D.; Hossain, M.; Ingram, L.; Kreider, R. 2012. Performance-related specifications for PCC pavements in Kansas, Journal of Materials in Civil Engineering 24(4): 479-487.

http://dx.doi.org/10.1061/(ASCE)MT.1943-5533.0000405

Haider, Z.M. 2009. A methodology to assess data variability and risk in a pavement design system for Bangladesh. Master of Philosophy Thesis, University of Birmingham.

Hoyos, L. R.; Puppala, A. J.; Ordonez, C. A. 2011. Characterization of cement-fiber-treated reclaimed asphalt pavement aggregates: preliminary investigation, Journal of Materials in Civil Engineering 23(7): 977-989. http://dx.doi.org/10.1061/(ASCE)MT.1943-5533.0000267

Hughes, C. S. 1996. Variability in highway pavement construction. National Cooperative Highway Research Program, Transportation Research Board.

Hughes, C. S.; McGhee, K. K.; Maupin Jr., G. W. 2007. The next step toward end-result specifications for hot-mix asphalt materials and construction, FHWA Report no. FHWA/ VTRC 07-R26, Virginia Transportation Research Council.

Hughes, C. S.; Simpson, A. L.; Cominsky, R.; Pendleton, O. J.; Weed, R. M.; Wilson, T. 1997. Measurement and specification of construction quality. Vol. 1: final report, FHWA Report No. FHWA-RD-98-077. 
Katicha, S. W.; Flintsch, G. W.; McGhee, K. 2011. Analysis of variability and normality assumption of the VDOT volumetric contractor data, in 2011 TRB Annual Meeting, 23-27 January 2011, Washington D.C.

Katicha, S. W.; Izeppi E.; Flintsch, G. W. 2010. Multivariate volumetric specifications and dynamic modulus as a quality measure for asphalt concrete materials. Report No. FHWA/VTRC 10-CR8.

Kenis, W.; Wang, W. 2000. Pavement variability and reliability. U.S. Department of Transportation, Federal Highway Administration.

Khazanovich, L.; Celauro, C.; Chadbourn, B.; Zollars, J.; Dai, S. 2006. Evaluation of subgrade resilient modulus predictive model for use in mechanistic-empirical pavement design guide, Transportation Research Record 1947: 155-166. http://dx.doi.org/10.3141/1947-15

Kim, H. B.; Buch, N. 2003. Reliability-based pavement design model accounting for inherent variability of design parameters, in $82^{\text {nd }}$ Transportation Research Board Annual Meeting, 12-16 January 2003, Washington D.C.

Manika, A.; Chatti, K.; Gopalakrishnan, K. 2012. Relating flexible pavement acceptance criteria to performance using MEPDG simulations and piecewise cubic spline interpolation, Journal of Civil Engineering and Management 18(1): 125-132.

http://dx.doi.org/10.3846/13923730.2012.657342

Mladenovic, G.; Jiang, Y. J.; Selezneva, O.; Aref, S.; Darter, M. 2003. Comparison of as-constructed and asdesigned flexible pavement layer thicknesses, Transportation Research Record 1853: 165-178. http://dx.doi.org/10.3141/1853-19

Mohammad, L. N.; Wu, Z.; Zhang, C.; Khattak, M. J.; Abadie, C. 2004, Variability of air void and mechanistic properties of plant produced asphalt mixtures, in $83^{\text {th }}$ Transportation Research Board Annual Meeting, 11-15 January 2004 Louisiana Transportation Research Center.

Múčka, P.; Granlund, J. 2012. Comparison of longitudinal unevenness of old and repaired highway lanes, Journal of Transportation Engineering 138(3): 371-380. http://dx.doi.org/10.1061/(ASCE)TE.1943-5436.0000297

NCHRP. 2004. Mechanistic-empirical design of new and rehabilitated pavement structures, National Cooperative Highway Research Program. NCHRP Project 1-37A, National Research Council, Washington, DC.

Noureldin, A. S.; Sharaf, E.; Arafah, A.; Al-Sugair, F. 1994. Estimation of standard deviation of predicted performance of flexible pavements using AASHTO model, Transportation Research Record 1449: 46-56.

Praticò, F. G. 2007. Quality and timeliness in highway construction contracts: a new acceptance model based on both mechanical and surface performance of flexible pavements, Construction Management and Economics 25(3): 305-313. http://dx.doi.org/10.1080/01446190601042426

Praticò, F. G. 2011. Pay adjustment in construction engineering, in 2011 International Conference on Business Intelligence and Financial Engineering, 12-13 December 2011, Hong Kong.

Praticò, F. G.; Casciano, A.; Tramontana, D. 2011. Pavement life-cycle cost and asphalt binder quality: theoretical and experimental investigation, Journal of Construction Engineering and Management 137(2): 99-107. http://dx.doi.org/10.1061/(ASCE)CO.1943-7862.0000264

Praticò, F. G.; Moro, A. 2007. Permeability and volumetrics of porous asphalt concrete: a theoretical and experimental investigation, Road Materials and Pavement Design 8(4): 799-817.

http://dx.doi.org/10.3166/rmpd.8.799-817
Praticò, F. G.; Moro, A.; Ammendola, R. 2009. Factors affecting variance and bias of non-nuclear density gauges for PEM and DGFC, The Baltic Journal of Road and Bridge Engineering 4(3): 99-107.

Praticò, F. G.; Moro, A.; Ammendola, R. 2010. Potential of fire extinguisher powders as filler in bituminous mixes, Journal of Hazardous Materials 173(1-3): 605-613. http://dx.doi.org/10.1016/j.jhazmat.2009.08.136

Retherford, J.; McDonald, M. 2010. Reliability methods applicable to mechanistic-empirical pavement design method, Transportation Research Record 2154: 130-137. http://dx.doi.org/10.3141/2154-13

Romanoschi, S. A.; Hossain, M.; Gisi, A.; Heitzman, M. 2004. Accelerated pavement testing evaluation of the structural contribution of full-depth reclamation material stabilized with foamed asphalt, Transportation Research Record 1896: 199-207. http://dx.doi.org/10.3141/1896-20

Russo, F.; Musolino, G. 2012. A unifying modelling framework to simulate the spatial economic transport interaction process at urban and national scales, Journal of Transport Geography 24: 189-197. http://dx.doi.org/10.1016/j.jtrangeo.2012.02.003

Seebaly, P. E.; Bazi, G. M. 2005. Impact of construction variability on pavement performance. Research Report no. 13DN-2. Nevada Department of Transportation.

Selezneva, O. I.; Jiang, Y. J. J.; Mladenovic, G. 2002. Evaluation and analysis of LTPP pavement layer thickness data. FHWA Final Report no. FHWA-RD-03-041.

Sherman, G. B. 1971. In situ materials variability, Special Report 126: 180-188. Highway Research Board.

Stubstad, R. N.; Tayabji, S. D.; Lukanen, E. O. 2002. LTPP data analysis: variations in pavement design inputs, NCHRP Web Document 48 (Project 20-50[5]): Contractor's Final Report.

Uddin, M.; Mohboub, K. C.; Goodrum, P. M. 2011. Effects of nonnormal distributions on highway construction acceptance pay factor calculations, Journal of Construction Engineering and Management 137(2): 108-118. http://dx.doi.org/10.1061/(ASCE)CO.1943-7862.0000268

Van Til, C. J.; McCullough, B.; Vallerga, A.; Hicks, R. G. 1972. Evaluation of AASHO interim guides for design of pavement structures. NCHRP 128, Highway Research Board.

Vazquez, C. G.; Aguiar-Moya, J. P.; Smit, A. F.; Prozzi, J. A. 2009. Laboratory evaluation of influence of operational tolerance (acceptance criterion) on performance of hotmix asphalt concrete. Center for Transportation Research, University of Texas at Austin.

Wang, H.; Hao, P.; Lu, G. 2009. Distribution properties of internal air void in asphalt mixtures, Journal of Traffic and Transportation Engineering 9(1): 6-11.

Weed, R. M. 2001. Derivation of equation for cost of premature pavement failure, in $80^{\text {th }}$ TRB Annual Meeting, 7-11 January 2001, Washington, DC.

Whiteley, L.; Tighe, S.; Zhang, Z. 2005. Incorporating variability into pavement performance models and life cycle cost analysis for performance-based specification pay factors, Journal of the Transportation Research Board 1940: 13-20. http://dx.doi.org/10.3141/1940-02

Zaniewski, J. P.; Hughes, M. 2006. Inter laboratory variability of the marshall test method for asphalt concrete. Final Report WVDOH RP \#137, West Virginia Department of Transportation, Division of Highways and U.S. Department of Transportation, Federal Highway Administration. 
Filippo Giammaria PRATICÒ. He earned his Laurea Degree in Civil Engineering from Pisa University and his PhD from Palermo University. After industrial occupation, he joined the Mediterranea University and became Associate Professor in 2002, serving as Deputy of the Master School, Deputy of the DIMET Department and Director of the Road Laboratory. Member of the Transportation Research Board of U.S. National Academies, he is Chair of several international committees. His research interests include civil engineering, sustainable engineering, materials, safety and management.

Antonio CASCIANO. He was born in Scilla (Reggio Calabria) in 1986. He earned his Laurea Degree in Civil Engineering from Mediterranea University of Reggio Calabria. After a period in industry (ANAS S.p.A.) he collaborated with the Road Laboratory of the University Mediterranea, where he took part to many international researches about Mechanistic-Empirical Pavement Design Guide (M-EPDG), quality assurance/quality control procedures (QA/QC), life cycle cost analysis, infrastructure asset management, road, railways and airport materials quality. Today, he works in an Italian industry (AVR S.p.A.) which performs highway maintenance and rehabilitation. His main papers deal with M-E PDG and QC/QA procedures. 